ELECTRONIC PAPER

\title{
Association between urinary 1-hydroxypyrene and genotoxic effects in coke oven workers
}

\author{
E Siwińska, D Mielżyńska, L Kapka
}

Occup Environ Med 2004;61:e10 (http://www.occenvmed.com/cgi/content/full/61/3/e10).

doi: $10.1136 /$ oem. 2002.006643

See end of article for authors' affiliations

Correspondence to:

Dr E Siwińska, Institute of Occupational Medicine and Environmental Health 13 Kościelna St, 41-200

Sosnowiec, Poland:

e.siwinska@imp.

sosnowiec.pl

Accepted

8 September 2003
Aims: To investigate whether current occupational exposure of coke oven workers to polycyclic aromatic hydrocarbons (PAHs) results in genotoxic effects measured in peripheral blood lymphocytes and whether these biomarkers are associated with the biomarkers of exposure.

Methods: Blood and urine samples were collected immediately after a shift at the end of a working week from 50 coke oven workers and 50 control workers not exposed to PAHs. Methods included: (1) biomarkers of exposure: urinary 1-hydroxypyrene $(\mathrm{HpU})$, urinary mutagenicity by the plate Salmonella test with strains TA98 and YG1024 after metabolic activation, expressed as mutagenic rate (MR98 and MR1024, respectively), urinary cotinine; and (2) biomarkers of biological effects in peripheral blood lymphocytes (PBL): sister chromatid exchanges (SCE/cell), cells of high frequency of SCE (\% HFC), micronuclei (MN/1000 cells), chromosomal aberrations (CA/100 cells), and DNA damage by the Comet assay.

Results: Occupational exposure to PAH resulted in significantly increased levels of $\mathrm{HpU}$ and mutagenic effect of urine. Median values of these biomarkers in coke oven workers were: $9.0 \mu \mathrm{mol} / \mathrm{mol}$ creatinine for $\mathrm{HpU}, 2.7$ for MR98, and 8.2 for MR1024, compared to the controls: $\mathrm{HpU}=0.6 \mu \mathrm{mol} / \mathrm{mol}$ creatinine, MR98 $=1.2$, and MR1024 =5.5. Occupational exposure caused significant induction of SCE, HFC, and $\mathrm{MN}$ in coke oven workers: median $\mathrm{SCE}=5.9, \mathrm{HFC}=12.0 \%, \mathrm{MN}=6.0$ compared to the controls: 3.9 , $5.0 \%$, and 3.0, respectively. No effect of occupational exposure was found in relation to CA and DNA damage measured with the Comet assay. HpU concentration was positively associated with SCE and HFC. The concentration of urinary 1-hydroxypyrene corresponding to a $5 \%$ probability of increased SCE was $1.0 \mu \mathrm{mol} / \mathrm{mol}$ creatinine.

Conclusions: The occupational exposure to PAHs resulted in measurable biological effects (SCE, HFC, MN). In coke oven workers an increased level of SCE was not observed below the level of $1.0 \mu \mathrm{mol} \mathrm{HpU/}$ mol creatinine.
$\mathrm{P}$ olycyclic aromatic hydrocarbons (PAHs) are the result of incomplete combustion of natural or synthetic organic materials. Both epidemiological and experimental evidence indicates that PAHs are carcinogenic to animals and possibly to human beings. ${ }^{1}$ The working environment at a coke plant can negatively affect the employed workers who are exposed to coke oven emissions containing PAHs formed and released into the environment when coal is pyrolysed into coke. ${ }^{2}$

The urinary excretion of l-hydroxypyrene (HpU), a metabolite of pyrene, has been used as a biological monitoring indicator of exposure to $\mathrm{PAHs}$ in several related occupational $^{3-10}$ and environmental ${ }^{1-14}$ studies. The measurement of urinary mutagenicity (Ames test) has been used to detect absorption of potentially mutagenic compounds as a non-specific biological marker of exposure. ${ }^{15}$ It has been used together with $\mathrm{HpU}$ determination to assess the exposure of coke oven workers to genotoxicants. ${ }^{76}$ There are several studies of the exposure to PAHs in which biomakers of biological effect measuring different kinds of genetic damage in peripheral blood lymphocytes have been used. ${ }^{6}{ }^{17-26}$

The investigations have been carried out in two Polish coke plants in order to establish whether the biomarkers of genotoxic effects such as sister chromatid exchanges (SCE), chromosomal aberrations (CA), micronuclei (MN) and DNA damage by Comet assay measured in peripheral blood lymphocytes (PBL) can be used to assess the effect of occupational exposure of coke oven workers, and whether these effects are associated with its intensity measured by markers of exposure ( $\mathrm{HpU}$ and urinary mutagenicity).

\section{MATERIALS AND METHODS Study population}

Fifty coke oven workers employed at two Polish coke oven plants participated in the study. Blood and urine samples were collected immediately after a shift at the end of working week. Fifty workers not exposed occupationally to PAHs and other genotoxic substances, employed at a large Polish steel factory were selected as the control group by the plant occupational hygiene service.

The coke oven workers participating in the study were classified into three main job categories as follows: (1) oven topside workers, $\mathrm{n}=20$; (2) oven coke-side workers, $\mathrm{n}=11$; and (3) oven push-side workers, $\mathrm{n}=19$.

All participants of this study gave their written consent. The study was accepted by the Ethic Committee of the Institute of Occupational Medicine and Environmental Health in Sosnowiec.

Abbreviations: CA, chromosomal aberrations; HFC, high frequency cells; $\mathrm{HpU}$, urinary 1-hydroxypyrene; $\mathrm{MN}$, micronuclei; MR, mutagenic rate of urine; SCE, sister chromatid exchanges; PAHs, polycyclic aromatic hydrocarbons 


\section{Main messages}

- The biomarkers of genotoxic effects-SCE, HFC, and $\mathrm{MN}$-are appropriate for surveillance studies of coke oven workers exposed to PAHs.

- The association found between the probability of increased SCE in PBL and 1-hydroxypyrene concentrations in post-shift urine suggests that $\mathrm{HpU}$ should not increase the level of $1.0 \mu \mathrm{mol} / \mathrm{mol}$ creatinine.

\section{Determination of 1-hydroxypyrene in urine}

The determination of $\mathrm{HpU}$ in urine was carried out using the HPLC method developed by Jongeneelen and Anzion. ${ }^{27} \mathrm{HpU}$ in the $10 \mathrm{ml}$ urine samples was enzymatically deconjugated and then transferred to primed C18 octadecyl cartridges (J. T. Baker), washed with $10 \mathrm{ml}$ of water, and eluted with $9 \mathrm{ml}$ of methanol. The components of the eluate were separated by means of high pressure liquid chromatography on the HP 1090 apparatus (Hewlett Packard) with the ODS C18, $200 \times 2.1 \mathrm{~mm}$ column, while $\mathrm{HpU}$ was quantitatively determined using the fluorescence detector HP 1046 (Hewlett Packard) with $229 \mathrm{~nm}$ excitation and $400 \mathrm{~nm}$ emission wavelengths.

The detection limit was $0.14 \mathrm{nmol}$ of $\mathrm{HpU}$ per litre of urine. $\mathrm{HpU}$ concentrations were expressed in $\mu \mathrm{mol} / \mathrm{mol}$ creatinine to account for differences in urine dilution.

\section{Determination of creatinine in urine}

Urinary creatinine concentrations were analysed using a standard colorimetric method following the picric acid reaction and absorption at $520 \mathrm{~nm}^{28}$

The reliability of $\mathrm{HpU}$ and creatinine concentration measurements were confirmed by the intralaboratory control, as well as by the intercomparison programme for occupational and environmental medical-toxicological analyses organised by the German Society for Occupational and Environmental Medicine in Erlangen. As a result, the Institute of Occupational Medicine and Environmental Health in Sosnowiec was granted the certificate for $\mathrm{HpU}$ analysis in occupational and medical applications.

\section{Urinary mutagenicity}

The analysis included the preparation of urine extracts according to the Yamasaki and Ames method. ${ }^{29}$ The organic substances present in urine were condensed using adsorption and desorption methods on columns filled with organic resin XAD-2. The extracts were examined by the aid of the Ames incorporation plate test. ${ }^{30}$ Before the examination the dichloromethane extracts of urine were dissolved in DMSO (dimethyl sulphoxide).

Three doses $(20,40,80 \mu \mathrm{l}$ of DMSO solution; representing $6,12,24 \mathrm{ml}$ of urine) were examined twice on two bacterial strains: TA 98 (from Prof. B M Ames) and YG 1024 (from Prof. T Nahomi), with metabolic activation (+S9 mixture).

Experimental points and the background mutation rate were used to calculate the least square regression line, using the volume of urine as an independent variable and revertant colonies per plate as the dependent variable. Using the equation of the regression line, the predicted value of dependent variable in $24 \mathrm{ml}$ of urine was calculated. Mutation effect was expressed as mutagenic rate $/ 24 \mathrm{ml}$ of urine.

To select the doses with a linear dose-response relation, a method of point rejection was applied. The assessment of data fitting to the model was done by the least square method involving regression analysis and analysis of variance

\section{Policy implications}

- Establishment of the quantitative relation between the level of 1-hydroxypyrene ( $\mathrm{HpU})$ and biological effect measured as SCE frequency can be used for preventive action in the coke oven industry.

instead of maximum likelihood method proposed by Bernstein, with the assumption of the significance level $p$ equal or lower than 0.05 .

The mutagenic rate (MR) is a ratio of a number of induced revertants to a number of revertants in the control sample. The control sample was prepared with redistilled water instead of urine and subjected to the same procedure as the urine samples (including DMSO and S9 mix). When the value of the mutagenic activity is $\geqslant 2$, the sample is considered to be mutagenic. Samples exhibiting toxic properties in the Ames test were excluded from statistical analysis.

\section{Determination of cotinine in urine}

The determination of cotinine was carried out using a high performance liquid chromatography (HPLC) method. A $10 \mathrm{ml}$ aliquot of urine from a sample was mixed with an internal standard (3,4-dihydrobenzylamine, $20 \mu \mathrm{g} / \mathrm{ml}$ ) and $1 \mathrm{ml}$ of saturated borate buffer, $\mathrm{pH}$ 9. The prepared sample was transferred into a tandem of octyl C-8 and silica gel columns ( $\mathrm{J}$ T Baker). Cotinine from columns was eluted with $1 \mathrm{ml}$ aliquots of $70 \%$ methylene chloride and 30\% methanol containing $1 \%$ ammonium hydroxide. The extract was dried under a nitrogen stream and then reconstructed in a $0.2 \mathrm{ml}$ mobile phase. Cotinine was determined by HPLC using an RP-C18 column (Serva) and a spectrophotometric detector $(\lambda=259 \mathrm{~nm})$. The mobile phase contained $88 \%$ water, $12 \%$ acetonitrile, $640 \mathrm{mg} / \mathrm{l}$ octanesulphonic acid sodium salt, and $5.95 \mathrm{~g} / \mathrm{K} \mathrm{K}_{2} \mathrm{HPO}_{4}$, $\mathrm{pH}$ adjusted to 4 using $\mathrm{H}_{3} \mathrm{PO}_{4}$. The range of determination was 50-2000 $\mathrm{ng} / \mathrm{ml}$. The low detection threshold was $20 \mathrm{ng} / \mathrm{ml}$ and the coefficient of variation below $10 \%{ }^{31}$

\section{Determination of cytogenetic endpoints in lymphocytes \\ Cultures}

Venous blood was taken from each subject using heparinised vacutainer tubes. Lymphocyte cultures were set up by adding $0.5 \mathrm{ml}$ of heparinised blood to $4.5 \mathrm{ml}$ of chromosome medium (RPMI 1640, Gibco) supplemented with 20\% heat inactivated fetal bovine serum (Gibco), antibiotics (penicillin and streptomycin), and L-glutamine. Lymphocytes were stimulated by $1 \%$ phytohaemagglutinin (Gibco).

\section{SCE assay}

The cultures were incubated for 72 hours at $37^{\circ} \mathrm{C}$ in $5 \% \mathrm{CO}_{2}$ with $0.25 \mathrm{ml}$ of 5-bromo-2'-deoxyuridine (BrdU, Sigma). Two hours prior to harvesting, Colcemid (Gibco) was added. The cells were collected by centrifugation, resuspended in a pre-warmed hypotonic solution $(0.075 \mathrm{M} \mathrm{KCl})$ for $20 \mathrm{~min}$ utes, and fixed in acetic acid:methanol (1:3, v/v). Chromosome preparations and stained slides were prepared following the Anthosina and Poriadkowa procedure. ${ }^{32}$

A total of 50 complete metaphases per donor were scored to determine the proportion of cells that underwent one, two, or three divisions. Data from $<50$ metaphases were discarded. The proliferate rate index (PRI) was calculated according to the formula PRI $=\left(M_{1}+2 M_{2}+3 M_{3}\right) / N$, where $M_{1}, M_{2}$, and $M_{3}$ indicate those metaphases corresponding to the first, second, and third divisions, and $\mathrm{N}$ is the total number of metaphases scored. ${ }^{33}$ 
The percentage of high frequency cells (HFC) for each individual was estimated using the pooled distribution of all SCE measurements. HFC was defined as cells that displayed over the 95th centile of the distribution of SCE per cell in the control population. ${ }^{34}$

\section{CA assay}

The cultures were incubated for 48 hours at $37^{\circ} \mathrm{C}$. Two hours prior to harvesting, colcemid was added to arrest the cells in metaphase. The cells were collected by centrifugation, resuspended in a pre-warmed hypotonic solution $(0.075 \mathrm{M}$ $\mathrm{KCl})$ for 25 minutes, and fixed in acetic acid:methanol (1:3, $\mathrm{v} / \mathrm{v})$. Air dried preparations were made and the slides were stained with Giemsa. A total of 100 well spread metaphases containing $46 \pm \mathrm{l}$ chromosomes was examined for each donor on coded slides, otherwise the data were discarded. ${ }^{35}$

\section{MN assay}

Briefly, the cultures were incubated at $37^{\circ} \mathrm{C}$ for 72 hours, and 44 hours after the initiation of cultures, cytochalasin-B (Sigma) at a concentration of $6 \mu \mathrm{g} / \mathrm{ml}$ was added to arrest cytokinesis. MN slides were stained with $10 \%$ Giemsa in phosphate buffer. A total of 1000 binucleates cells with well preserved cytoplasm was examined for each subject on coded slides and the total number of $\mathrm{MN}$ and the frequency of binucleated cells with MN (BNMN) were scored. ${ }^{36}$

\section{Comet assay}

The test was performed on whole blood cells under alkaline conditions. ${ }^{37}$ The slides containing agarose embedded cells were first immersed in cold, freshly prepared lysing solution (2.5 M NaCl, $100 \mathrm{mM} \mathrm{Na}{ }_{2}$ EDTA, $10 \mathrm{mM}$ Tris-HCl, $1 \%$ lauroyl sarcosinate, $1 \%$ Triton $\mathrm{X}-100$; $\mathrm{pH} 10$ ) for a minimum of one hour at $4{ }^{\circ} \mathrm{C}$, to lyse the cells and allow DNA to unfold. After 20 minutes of DNA unwinding in ice cold, high $\mathrm{pH}$ electrophoresis buffer ( $1 \mathrm{mM} \mathrm{Na}{ }_{2}$ EDTA, $300 \mathrm{mM} \mathrm{NaOH}$, $\mathrm{pH}$ 13), electrophoresis was conducted for 30 minutes at $25 \mathrm{~V}(300 \mathrm{~mA})$. The slides were then neutralised with dropwise $0.4 \mathrm{M}$ Tris- $\mathrm{HCl}$ ( $\mathrm{pH} 7.5)$, washed three times for five minutes, and stained with $60 \mu \mathrm{l}$ of a $4^{\prime} 6$-di-amidino-2phenylindole dihydrochloride (DAPI) solution.

Slides were then visually examined using a fluorescence microscope. One hundred cells were scored at $400 \times$ magnification, and mean comet length was calculated for each subject. Moreover, cells were graded visually into five categories (0-4) according to the amount of DNA in the tail, where 0 indicates undamaged cells and 4 indicates highly damaged cells.

\section{Questionnaire}

A self administered questionnaire was used to determine present health status; age; duration of occupational exposure; diet; smoking habits; additional sources of exposure at the dwelling site (industrial plants, heavy traffic); heating system; $x$ ray exposition; incidents of cancer diseases in family.

\section{Statistical analysis}

Responses to the questionnaire and analytical data were stored in a database and statistically analysed using STATISTICA for Windows, version 9.9, 1997.

The data were examined for normal distribution by the $\chi^{2}$ test. Since most variables were not normally distributed we decided to use non-parametric descriptive statistics (medians and quartiles). Comparisons between two samples were performed by the Mann-Whitney U test.

Multiple regression analysis was used to identify the factors which influenced biomarkers of exposure and effects. When necessary ( $\mathrm{HpU}, \mathrm{MR}, \mathrm{HFC}, \mathrm{MN})$ the variable distribution was normalised by log transformation. Except for the smoking habit, the assessment of which was based on urinary cotinine determination (non-smoking: cotinine concentration $\leqslant 400 \mathrm{ng} / \mathrm{ml}=0$; smoking $>400 \mathrm{ng} / \mathrm{ml}=1$ ), confounding factors were assessed according to responses to the questionnaire and included: age (years), duration of occupational exposure to PAHs (for coke oven workers, years), intake of grilled meals ( 1 if at least three meals per week; otherwise 0 ), intake of home grown vegetables and fruit ( 0 if no; 1 if yes, because of high environmental pollution in this region), additional sources of environmental pollution at a dwelling site ( 0 or 1$)$, heating system (presence of coal burning stoves inside flats $=1$, other heating systems $=0$ ), plant index ( 1 for the coke plant, 0 for control group), permanent intake of medicines ( 0 or 1$)$, medicines taken recently $(0$ or 1$), x$ ray exposition during the six months previous to sampling ( 0 or 1 ), incidences of cancer diseases in family (0 or 1$)$.

To assess the relation between biomarkers of exposure and effect, Spearman rank correlation analysis was applied on the data of the total population.

The determinants of increased prevalence of abnormal values of the variables were identified by applying a logistic regression model to the data of total population: independent continuous variables (HpU, MR98, and MR1024 - lognormal) versus dependent categorical variables (SCE and MN). Dependent variables were considered abnormal when they exceeded the 95th centile value of the respective distribution in the control group ( $\mathrm{SCE} / \mathrm{cell} \geqslant 5=1, \mathrm{SCE} /$ cell $<5=0$; $\mathrm{MN}$ $\geqslant 1 \mathrm{l}=1, \mathrm{MN}<\mathrm{ll}=0$; HFC were excluded because of the small number of data). The odds ratios with $95 \%$ confidence limits were calculated to assess the extent of influence of significant parameters on the increased prevalence of abnormal values of cytogenetic effects.

\section{RESULTS}

All subjects participating in the study filled in a questionnaire. Table 1 presents the characteristics of the control workers and workers exposed to PAHs. The mean age of exposed workers was slightly lower than that of the control group. Both groups were well matched with regard to their socioeconomic status (workers) and smoking habits. The number of smokers was higher in the exposed group but the increase was not significant. Not significant difference between two groups was also noticed regarding the level of urinary cotinine.

The level of exposure to PAHs and other mutagenic substances was assessed by two biomarkers of exposure: urinary l-hydroxypyrene and urinary mutagenicity measured by the Salmonella (Ames) test with TA98 (MR 98) and YG1024 (MR 1024) strains with metabolic activation (+S9mix) (table 2). A significant difference between the control group and the coke oven workers concerning both biomarkers was observed. Urinary l-hydroxypyrene and mutagenic activity were analysed for their association with confounding factors. Of 12 examined factors, only one-

\begin{tabular}{|c|c|c|c|}
\hline Parameters & $\begin{array}{l}\text { Control } \\
(n=50)\end{array}$ & $\begin{array}{l}\text { Coke oven } \\
(n=50)\end{array}$ & $p$ value \\
\hline Age (years) ${ }^{*}$ & $43.6(6.3)$ & $40.2(7.8)$ & 0.017 \\
\hline $\begin{array}{l}\text { Years of exposure to PAHs* } \\
\text { Number of smokers } \\
\text { (questionnaire) }\end{array}$ & $24(48 \%)$ & $\begin{array}{l}16.0(7.9) \\
33(66 \%)\end{array}$ & \\
\hline
\end{tabular}


Table 2 Biomarkers of exposure in coke oven and control workers

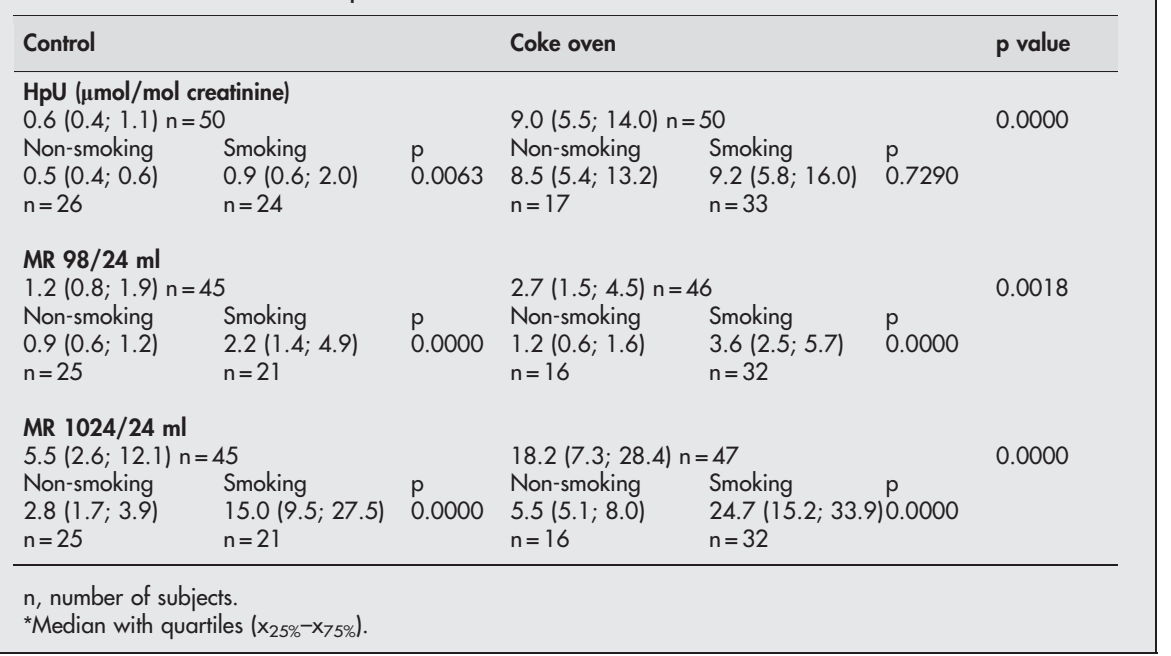

smoking habit—affected the level of biomarkers of exposure. The smoking habit significantly increased the level of $\mathrm{HpU}$ only in the control group and the level of MR 98 and 1024 both in the exposed and not exposed workers (table 2). Significant positive correlation was obtained between l-hydoxypyrene excretion and urinary mutagenicity, both for MR98 $\left(r_{s}=0.478\right)$ and MR $1024\left(r_{s}=0.606\right)$.

No differences in the level of two biomarkers of biological effects-CA and DNA damage measured by the Comet assay-were observed between the control and exposed group. The mean length of comets was even lower in coke oven workers than in the control group.

Other effect biomarkers (SCE, HFC, and MN) were, however, significantly higher in coke oven workers (table 3) but their level was not associated with the duration of occupational exposure. The proliferation rate index was slightly decreased, ranging from 1.9 in the control group to 1.8 in the occupational group. No confounding factor influenced the level of biomarkers of effects except for the smoking habit which affected HFC, but only in cases when all data were analysed together (coke oven workers + control group). The median HFC in smokers was $10 \%(\mathrm{n}=31)$ and in non-smokers $6 \%(\mathrm{n}=26)$.

Nearly all of the studied relations between the biomarkers of exposure and biomarkers of effect revealed significant positive correlation with varying strengths of associations (table 4). Figure 1 presents the relation between the number of SCE/cell in lymphocytes and urinary HpU concentration in exposed and control subjects.

A logistic regression analysis was performed to identify the determinants of increased prevalence of abnormal values of biomarkers of effects (dependent categorical variables). Exposure parameters (MR98, MR1024, and HpU) were independent variables and confounding factors were the same as listed in statistical methods. It was found that the concentration of $\mathrm{HpU}$ in urine was positively associated with an increased odds ratio for SCE. MN results were excluded from the analysis because only $12 \%$ of coke oven workers had the number of micronuclei higher than the value of the 95th centile in the control group. The odds ratio for SCE was 3.94 - that is, one unit increase of $\log (\mathrm{HpU})$ rendered the risk of the prevalence of increased SCE (SCE/cell $\geqslant 5$ ) nearly four times higher than the chance that the level of SCE would be below the $5 \mathrm{SCE} / \mathrm{cell}$. Since logistic regression analysis revealed no confounding effect of smoking, the relation was established for all data, including smokers (fig 2). The concentration of $\mathrm{HpU}$ that corresponds to a $10 \%$ probability of increased SCE values was $1.8 \mu \mathrm{mol} / \mathrm{mol}$ creatinine. The prevalence of increased SCE values in lymphocytes did not significantly exceed the background level (5\%) when the mean concentration of $\mathrm{HpU}$ in post-shift urine did not exceed $1.0 \mu \mathrm{mol} / \mathrm{mol}$ creatinine (table 5 ). The values of coefficients of the logistic regression equation: $y=e(b+a x) /\left(1+e^{b+a x}\right)$ (with standard errors) were as follows: $b=-3.0111(0.6907)$, $\mathrm{p}=0.00004$; and $\mathrm{a}=1.3709$ (0.3293), $\mathrm{p}=0.00008$. When the logistic regression analysis was applied to the subjects exposed to PAHs only occupationally, the exposure duration did not influence significantly any of the biomarkers of effect.

\section{DISCUSSION}

Current occupational exposure to PAHs was investigated in Polish coke oven plants in order to establish whether they resulted in biological effects which are considered to be indicators for long term adverse health effects. Biological monitoring of the internal dose was based on the analysis of urinary 1-hydroxypyrene and urinary mutagenicity by the Salmonella assay with TA98 and YG1024 after metabolic activation. Biological effect monitoring involved SCE, HFC, CA, and DNA damage by the Comet assay.

Table 3 Biomarkers of effects in coke oven and control workers

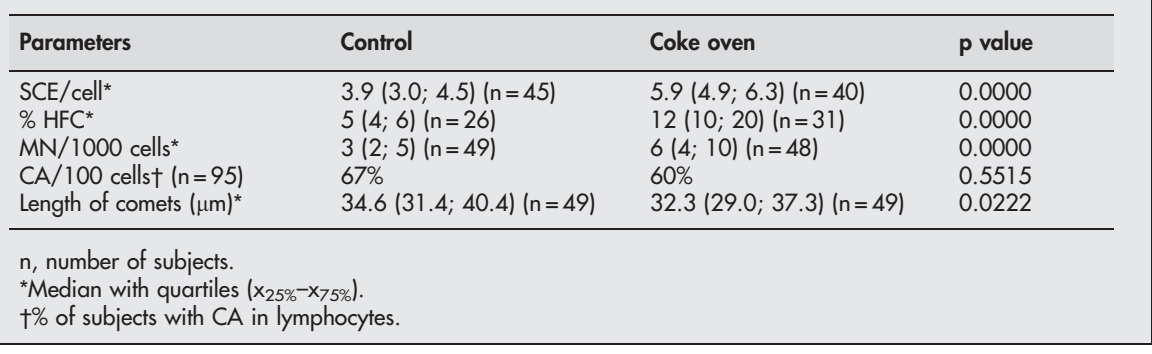




\begin{tabular}{|c|c|c|}
\hline & \multicolumn{2}{|c|}{ Spearman rank correlation } \\
\hline & $\mathbf{r}_{\mathrm{s}}$ & $\mathbf{p}$ \\
\hline \multicolumn{3}{|c|}{$\mathrm{HpU}(\mu \mathrm{mol} / \mathrm{mol}$ creat $) v$} \\
\hline SCE $(n=85)$ & 0.80 & 0.0000 \\
\hline $\mathrm{HFC} \%(n=57)$ & 0.91 & 0.0000 \\
\hline$M N(n=97)$ & 0.35 & 0.0005 \\
\hline \multicolumn{3}{|l|}{ MR $98 / 24 \mathrm{ml} \mathrm{v}$} \\
\hline SCE $(n=77)$ & 0.30 & 0.0076 \\
\hline HFC $(n=53)$ & 0.46 & 0.0005 \\
\hline$M N(n=88)$ & 0.25 & 0.0196 \\
\hline \multicolumn{3}{|c|}{ MR $1024 / 24 \mathrm{ml} \mathrm{v}$} \\
\hline SCE $(n=78)$ & 0.45 & 0.0000 \\
\hline HFC $(n=53)$ & 0.53 & 0.0000 \\
\hline$M N(n=89)$ & 0.21 & 0.0501 \\
\hline
\end{tabular}

$n$, number of subjects; $r_{s}$ Spearman rank correlation coefficient.

In our study the clear internal occupational exposure related to urinary l-hydroxypyrene concentration and urinary mutagenicity was found. Many studies aiming at the assessment of the internal exposure of coke oven workers to PAHs were based on the determination of HpU. The concentrations of this biomarker in urine of coke oven workers were up to $20 \mu \mathrm{mol} / \mathrm{mol}$ creatinine. $^{38}$ Later investigations performed in West European coke oven workers revealed lower levels of $\mathrm{HpU}$, not exceeding in average the concentration of $2 \mu \mathrm{mol} / \mathrm{mol}$ creatinine. ${ }^{1039} 40$ Contrary to this tendency, the internal exposure to PAHs of Polish coke oven workers tends to increase from the level of $3.6 \mu \mathrm{mol} / \mathrm{mol}$ creatinine ${ }^{7}$ to $9.0 \mu \mathrm{mol} / \mathrm{mol}$ creatinine (table 2).

Jongeneelen proposed an end-of-working-week biological exposure limit of $2.3 \mu \mathrm{mol} \mathrm{HpU} / \mathrm{mol}$ creatinine as the concentration equalling the TWA-TLV of $0.2 \mathrm{mg} / \mathrm{m}^{3}$ of benzene soluble matter (BSM). ${ }^{41}{ }^{42}$ Only one member of our occupational group had the level of $\mathrm{HpU}$ lower than the proposed benchmark guideline for coke oven workers.

In his review of many papers on $\mathrm{HpU}$ as a biomarker of exposure to PAHs, Bouchard ${ }^{43}$ found that some authors

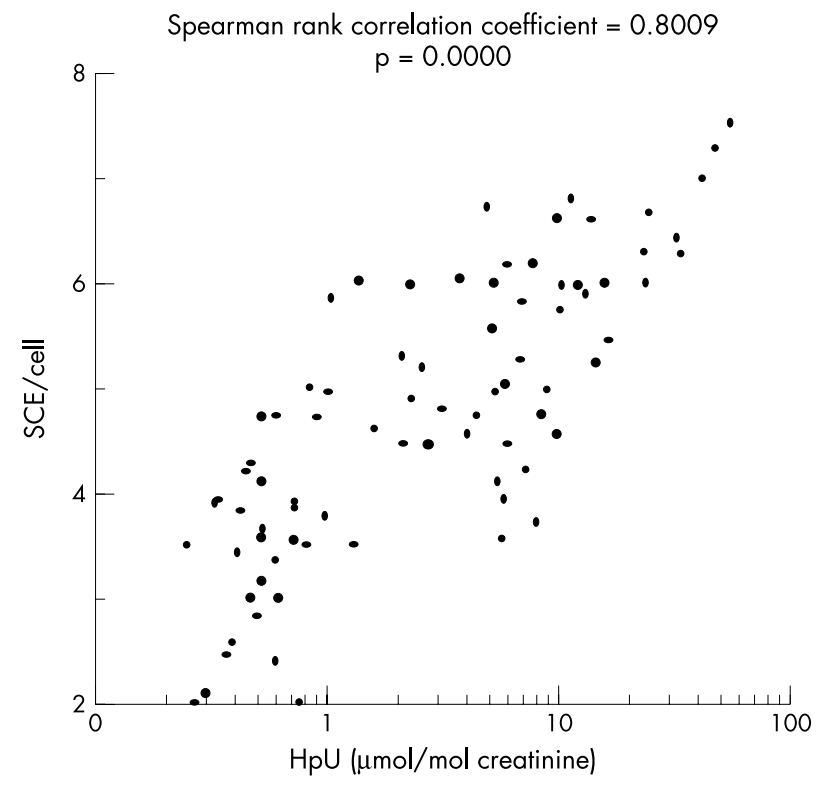

Figure 1 Relation between SCE in lymphocytes and $\mathrm{HpU}$ concentration in post-shift urine of exposed and control population $(n=85)$.

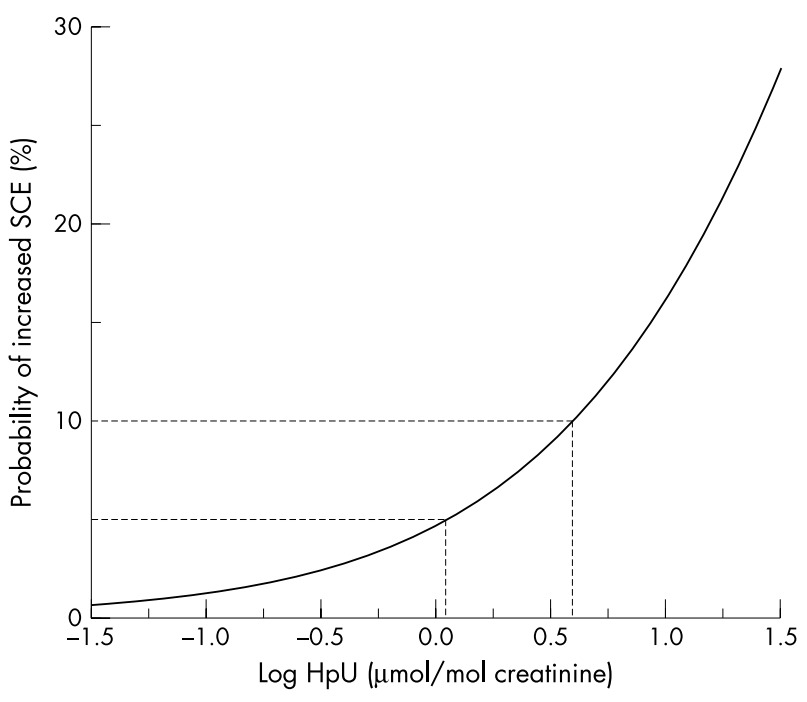

Figure 2 Probability of increased SCE as a function of $\mathrm{HpU}$ concentration in post-shift urine.

suggested a synergistic effect of smoking in combination with $\mathrm{PAH}$ exposure in the work environment on the excretion of 1-hydroxypyrene in urine. On the other hand in several other studies smoking caused a significant increase in urinary $\mathrm{HpU}$ concentrations only in subjects not occupationally exposed to PAHs, and the differences in $\mathrm{HpU}$ excretion between smokers and non-smokers disappeared as exposure levels increased. Our investigations confirmed these findings. The only difference in $\mathrm{HpU}$ level between smokers and non-smokers was found among the control subjects. Smoking habit did not influence the differences between the exposed and not exposed workers, probably because of the high exposure to PAHs of coke oven workers which could hide the effect of smoking on HpU level. Similar results were obtained by Zhang and colleagues, ${ }^{9}$ but they found significant difference as regards smoking related $\mathrm{HpU}$ levels neither in the occupational nor in the control group subjects.

Some research projects involved the determination of urinary mutagenicity as a biomarker of exposure of coke oven workers to PAHs. The results indicated that urinary mutagenicity was not or only slightly related to occupational exposure and strongly affected by smoking. ${ }^{214-46}$ Other research revealed that although coke oven workers excreted significantly more mutagenic substances in urine than the controls, still the most clear cut difference was between smokers and non-smokers. ${ }^{7}{ }^{16} 47-49$ In our study we found a clear increase of mutagenic rate in coke oven workers' urine with both bacterial strains, but although the increase was significant the influence of smoking on urinary mutagenicity was greater than the effect of exposure. Additionally to the strain TA98 which is usually used in detecting the exposure to PAHs, we used its derivative YG1024 which overproduces acetyltransferase and is highly sensitive to the mutagenicity

Table 5 The association of HPU concentration with the probability of increased SCE (exposed + control population)

\begin{tabular}{ll}
\hline Probability of increased SCE & $\mathrm{HpU}(\mu \mathrm{mol} / \mathrm{mol}$ creatinine) \\
\hline $5 \%$ & 1.0 \\
$10 \%$ & 1.8 \\
\hline
\end{tabular}


of nitroarenes and aromatic amines. YG1024 turned out to be up to six times more sensitive than its parent strain as regards both the occupational and control group. It is worth mentioning that mutagenic substances were detected also in the control group, indicating environmental exposure of the general Silesian population. We found that $100 \%$ of urine samples collected from coke oven workers were mutagenic towards YG1024 compared with $78 \%$ in the control group. The association between mutagenic rate of urine detected with both strains and HpU level was significant, confirming our previous findings that mutagenic effect of urine is a useful tool in assessing occupational exposure to PAHs at the group level. ${ }^{7}$

The assessment of health risks due to PAH exposure based on the concentration of 1-hydroxypyrene in urine requires an established quantitative relation between the HpU level and health effects measured in the exposed population. Some authors have investigated the association between HpU and biologically effective dose evaluated by measuring adducts formed between electrophilic metabolites of PAHs and DNA in white blood cells or blood proteins (the investigations were reviewed in Bouchard ${ }^{43}$ ). However, studies on the relation between 1-hydroxypyrene excretion and genotoxic effects in workers exposed to PAHs, especially in coke oven workers are very scarce. In some biomonitoring studies of coke oven workers, biological effects like SCE, HFC, or CA were shown to be increased due to PAH exposure, ${ }^{6} 192022232526$ where as in other studies no effects were observed. ${ }^{101721}$ In several studies the associations between the occupational exposure to PAHs and biological effects were detected only in workers who smoked cigarettes. ${ }^{621}{ }^{24}$ A significantly increased level of chromosomal aberrations in lymphocytes of coke oven workers was found in very few research projects. ${ }^{20}{ }^{26}$ To our knowledge no published data on significant induction of MN in coke oven workers are available, although this biomarker was applied in some biomonitoring occupational studies. ${ }^{6}{ }^{10} 212324$ In most research involving coke oven workers SCE and HFC appeared to be more sensitive cytogenetic biomarkers for biomonitoring of exposure to PAHs than CA or MN frequencies, and the results of our study confirm that finding. However, this study showed also the usefulness of $\mathrm{MN}$ in monitoring populations occupationally exposed to PAHs. Unfortunately we did not observe the occupationally induced increase of chromosomal aberrations-so far the only one out of three cytogenetic markers (SCE, CA, MN) that has been considered to have a predictive value for cancer risk. $^{50}$

The comet assay has been increasingly popular over the past 10 years. The version described by Singh and colleagues (1988) has been the protocol of choice in biomonitoring studies. The end point measured by this traditional comet assay is a mixture of direct strand breaks and DNA damage that is converted to strand breaks by alkaline treatment. The term "DNA damage" is used to encompass all types of damage detected by the traditional comet assay. ${ }^{51}$ In very few studies was the comet assay used as a method of monitoring occupational exposure of coke oven workers. Marczynski and colleagues $^{40}$ and Popp and colleagues, ${ }^{17}$ using the alkaline filter elution assay, found significantly more DNA strand breaks in coke oven workers than in the controls. In our study the comet assay did not prove to be a good tool in assessing occupational exposure of coke oven workers to PAHs. The level of DNA damage determined by the length of the comet tail did not show increase in the occupational group. Similarly Van Delft and colleagues ${ }^{10}$ did not find significant differences in DNA strand breaks between controls and coke oven workers. Furthermore, no smoking or GSTMI and GSTT1 genetic polymorphism related effect was observed in their study.
Although it has frequently been shown that tobacco smoking results in increased levels of biomarkers of effect, various studies often provide mixed results. Smoking induced the formation of genetic endpoints such as SCE, HFC, or DNA strand breaks in some studies ${ }^{6} 17212224$ while in others (or referring to other biomarkers) no effect of smoking was reported. ${ }^{10232640}$ As in the latest studies, smoking did not influence significantly any of the applied biomarkers of effect in Polish coke oven workers.

The influence of exposure duration (in years) of coke oven workers on the level of effect biomarkers was examined by Buchet and colleagues. ${ }^{6}$ They did not identify exposure duration as a statistically significant determinant of any of the biomarkers of effects. Our study confirmed that finding, which may suggest that these biomarkers mainly reflect recent exposure to genotoxic chemicals.

Since epidemiological studies of cancer mortality related to long term average urinary l-hydroxypyrene concentration are not available and a sound health based limit value of $\mathrm{HpU}$ cannot be set as yet, Jongeneelen ${ }^{42}$ made an attempt to propose a three level benchmark guideline for urinary 1-hydroxypyrene. The second level of the benchmark guideline-a no-biological-effect level-is the highest reported level of 1-hydroxypyrene in urine of exposed workers at which increased genotoxic effects were not observed. This benchmark guideline was based on the research of Buchet and colleagues, ${ }^{6}$ who measured cytogenetic endpoints in lymphocytes of Belgian workers exposed to PAHs, including coke oven workers and in the controls. A logistic regression analysis revealed that post-shift $\mathrm{HpU}$ concentration was positively associated with an increased odds ratio for HFC. In view of the confounding effect of smoking they established the relation for smokers and non-smokers separately. They found that in the non-smoking workers the prevalence of the increased HFC values in lymphocytes did not significantly exceed the background level (5\%) when the HpU concentration in post-shift urine did not exceed $2.7 \mu \mathrm{g} / \mathrm{g}$ creatinine ( $1.4 \mu \mathrm{mol} / \mathrm{mol}$ creatinine). ${ }^{6}$ Jongeneelen proposed the level of $1.4 \mu \mathrm{mol} / \mathrm{mol}$ creatinine as the second level of the benchmark guideline. ${ }^{42}$

In our study we aimed to confirm the results of Buchet and colleagues, ${ }^{6}$ performing the same analysis on the data of Polish coke oven workers. Since we did not find a confounding effect of smoking, the association of the concentration of $\mathrm{HpU}$ with the probability of increased SCE included all data. The results revealed that for preventive action it seems better to maintain the exposure to PAHs at a level which prevents an increased prevalence of this biomarker-that is, below the $\mathrm{HpU}$ concentration of $1.0 \mu \mathrm{mol} / \mathrm{mol}$ creatinine. However, although SCE is an established biomarker of exposure for mutagens or carcinogens in the work environment, the long term health significance of increased SCE is still unknown, and it is not clear whether that biomarker may serve as a biomarker for a genotoxic effect resulting in an enhanced cancer risk. Unless such an association is observed, a sound biological exposure limit based on the relation SCE-HpU cannot be proposed, the more so as no induction of CA in PBL of coke oven workers was observed in our study.

In conclusion, we found that occupational exposure of coke oven workers resulted in significantly increased levels of biomarkers of exposure ( $\mathrm{HpU}$ and mutagenic rate) and some biomarkers of effect (SCE, HFC, and MN). SCE and HFC were more sensitive than MN frequencies for biomonitoring of the exposure to PAHs. The association found between the probability of increased SCE values and 1-hydroxypyrene concentrations in post-shift urine suggests that $\mathrm{HpU}$ should not increase the level of $1.0 \mu \mathrm{mol} / \mathrm{mol}$ creatinine. 


\section{ACKNOWLEDGEMENTS}

The study was supported by the Polish Committee of Scientific Research (grant no. 4 PO5D 014 18).

\section{Authors' affiliations}

E Siwińska, D Mielżyńska, L Kapka, Institute of Occupational Medicine and Environmental Health, 13 Kościelna St, 41-200 Sosnowiec, Poland

\section{REFERENCES}

1 International Agency for Research on Cancer (IARC). Overall evaluation of carcinogenicity: an updating of IARC monographs. IARC Monographs 1987; (suppl 6-7): 1-42

2 Ming-Tsang Wu, I-Fang Mao, Chi-Kung Ho, et al. Urinary 1-hydroxypyrene concentrations in coke oven workers. Occup Environ Med 1998;55:461-7.

3 Jongeneelen FJ, Anzion RBM, Scheepers PTJ, et al. 1-Hydroxypyrene in urine as a biological indicator of exposure to polycyclic aromatic hydrocarbons in several work environments. Ann Occup Hyg 1988;3:35-43.

4 Jongeneelen FJ, Leeuwen FE, Oosterink S, et al. Ambient and biological monitoring of cokeoven workers: determinants of the internal dose of polycyclic aromatic hydrocarbons. Br J Ind Med 1990;47:454-61.

5 Van Rooij JGM, Bodelier-Bade MM, Jongeneelen FJ. Estimation of the individual dermal and respiratory uptake of polycyclic aromatic hydrocarbons of 12 cokeoven workers. Br J Ind Med 1993;50:623-32.

6 Buchet JP, Ferreira M, Burrion JB, et al. Tumor markers in serum, polyamines and modified nucleosides in urine, and cytogenetic aberrations in lymphocytes of workers exposed to polycyclic aromatic hydrocarbons. Am J Ind Med 1995;27:523-43.

7 Mielżyńska D, Braszczyńska Z, Siwińska E, et al. Exposure of coke-oven workers to polycyclic aromatic hydrocarbons based on biological monitoring results. Am Ind Hyg Assoc J 1997;58:661-6.

8 Pan G, Tanaoka T, Yamano Y, et al. A study of multiple biomarkers in coke oven workers - a cross-sectional study in China. Carcinogenesis 1998; 19:1963-8.

9 Zhang J, Ichiba M, Hara K, et al. Urinary 1-hydroxypyrene in coke oven workers relative to exposure, alcohol consumption, and metabolic enzymes. Occup Environ Med 2001;58:716-21.

10 Van Delft JHM, Steenwinkel MJ, Van Asten JG, et al. Biological monitoring the exposure to polycyclic aromatic hydrocarbons of coke oven workers in relation to smoking and genetic polymorphisms for GSTM1 and GSTT1. Ann Occup Hyg 2001;45:395-408.

11 Kanoh T, Fukuda M, Onozuka H, et al. Urinary 1-hydroxypyrene as a marker of exposure to polycyclic aromatic hydrocarbons in environment. Environ Res 1993:62:230-41

12 Øvrebø S, Fjeldstad PE, Grzybowska E, et al. Biological monitoring of polycyclic aromatic hydrocarbon exposure in a highly polluted area of Poland. Environ Health Perspect 1995; 103:838-43.

13 Siwińska E, Mielżyńska D, Bubak A, Smolik E. The effect of coal stoves and ETS on the level of urinary 1-hydroxypyrene. Mutat Res 1999;445:147-53.

14 Scherer G, Frank S, Riedel K, et al. Biomonitoring of exposure to polycyclic aromatic hydrocarbons of nonoccupationally exposed persons. Cancer Epidemiol Biomarkers Prev 2000;9:373-80.

15 Sorsa M, Hemminki K, Vainio H. Biologic monitoring of exposure to chemical mutagens in the occupational environment. Teratog Carcinog Mutagen 1982;2:137-150

16 Ferreira $M$ Jr, Buchet JP, Burrion JB, et al. Determinants of urinary thioethers, d-glucaric acid and mutagenicity after exposure to polycyclic aromatic hydrocarbons assessed by air monitoring and measurement of 1 hydroxypyrene in urine: a cross-sectional study in workers of coke and graphite-electrode-producing plants. Int Arch Occup Environ Health 1994:65:329-38

17 Popp W, Vahrenholz C, Schell C, et al. DNA single strand breakage, DNA adducts, and sister chromatid exchange in lymphocytes and phenanthrene metabolites in urine of coke oven workers. Occup Environ Med 1997:54:176-83.

18 Järvholm B, Nordström G, Högstedt B, et al. Exposure to polycyclic aromatic hydrocarbons and genotoxic effects on nonsmoking Swedish road pavement workers. Scand J Work Environ Health 1999;25:131-6.

19 Miner JK, Rom WN, Livingston GK, et al. Lymphocyte sister chromatid exchange (SCE) frequencies in coke oven workers. J Occup Med 1983:25:30-3.

20 Bender MA, Leonard RC, White $\mathrm{O} \mathrm{Jr}$, et al. Chromosomal aberrations and sister-chromatid exchanges in lymphocytes from coke oven workers. Mutat Res 1988;206:11-16

21 Reuterwall C, Aringer L, Elinder CG, et al. Assessment of genotoxic exposure in Swedish coke-oven work by different methods of biological monitoring. Scand J Work Environ Health 1991;17:123-32.
22 Motykiewicz G, Michalska J, Pendzich J, et al. A cytogenetic study of men environmentally and occupationally exposed to airborne pollutants. Mutat Res 1992;280:253-9.

23 Van Hummelen P, Gennart JP, Buchet JP, et al. Biological markers in PAH exposed workers and controls. Mutat Res 1993;300:231-9.

24 Forni A, Guanti G, Bukvic N, et al. Cytogenetic studies in coke oven workers. Toxicol Lett 1996;88:185-9.

25 Wang $X$, Chen $C$, Wu Y, et al. Detection of sister chromatic exchange in workers exposed to coal tar pitch and to coke oven volatiles. Wei Sheng Yan Jiv 1998;27:220-1.

26 Kalina I, Brezani P, Gajdosova D, et al. Cytogenetic monitoring in coke oven workers. Mutat Res 1998;417:9-17.

27 Jongeneelen FJ, Anzion RBM. Analyses of hazardous substances in biological materials. Deutsche Forschungsgemeinschaft 1990;3:151-69.

28 Baselt RC. Biological monitoring methods for industrial chemicals. Davis, CA: Biomedical Publications, 1980:207-11

29 Ames BN, McCann J, Yamasaki E. Methods for detecting carcinogens and mutagens with the Salmonella/mammalian-microsome mutagenicity test. Mutat Res 1975;31:347-64.

30 Yamasaki E, Ames BN. Concentration of mutagens from urine by adsorption with the non-polar resin XAD-2: cigarette smokers have mutagenic urine. Proc Natl Acad Sci 1977;74:3555-9.

31 Pach J, Piekoszewski W. The preliminary study of the addictive substances used by high school students. Acta Poloniae Toxicol 2000;8:179-85.

32 Anthosina M, Porjadkowa N. A technique for differential staining of sister chromatid without using fluorochrome. Citol Genet 1978:4:349-52.

33 Lamberti L, Bigatti Ponzetto P, Ardito G. Cell kinetics and sister chromatid exchange frequency in human lymphocytes. Mutat Res 1983;120:193-9.

34 Moore II DH, Carrano AV. Statistical analysis of high SCE frequency. In: Tice RR, Hollaender A, eds. Sister chromatid exchanges. New York: Plenum, 469-80)

35 Carrano AV, Natarajan AT. Consideration for population monitoring using cytogenetic techniques. Mutat Res 1988;204:379-406.

36 Pitarque $M$, Carbonell $E$, Lapena $N$, et al. No increase in micronuclei frequency in cultured blood lymphocytes from a group of filling station attendants. Mutat Res 1996;367:161-7.

37 Singh NP, McCoy MT, Tice RR, et al. A simple technique for quantitation of low levels of DNA damage in individual cells. Exp Cell Res 1988; 175: 184-91.

38 Levin JO. First international workshop on hydroxypyrene as a biomarker for PAH exposure in man - summary and conclusions. The Science of the Total Environment 1995; 163:165-8.

39 Ovrebo S, Ryberg D, Haugen A, et al. Glutathione S-transferase M1 and P1 genotypes and urinary excretion of 1-hydroxypyrene in coke oven workers. The Science of the Total Environment 1998;220:25-31

40 Marczyński B, Rihs HP, Rossbach B, et al. Analysis of 8-oxo-7,8-dihydro-2'deoxyguanosine and DNA strand breaks in white blood cells of occupationally exposed workers: comparison with ambient monitoring, urinary metabolites and enzyme polymorphisms. Carcinogenesis 2002;23:273-81

41 Jongeneelen FJ. Biological exposure limit for occupational exposure to coa tar pitch volatiles at coke-ovens. Int Arch Occup Environ Health 1992;63:511-16

42 Jongeneelen FJ. Benchmark guideline for urinary 1-hydroxypyrene as biomarker of occupational exposure to polycyclic aromatic hydrocarbons. Ann Occup Hyg 2001;45:3-13.

43 Bouchard M, Viau C. Urinary 1-hydroxypyrene as a biomarker of exposure to polycyclic aromatic hydrocarbons: biological monitoring strategies and methodology for determining biological exposure indices for various work environments. Biomarkers 1999:4:159-87.

44 Möller M, Dybing E. Mutagenicity studies with urine concentrates from coke plant workers. Scand J Work Environ Health 1980;6:216-20.

45 Kriebel D, Commoner B, Bollinger D, et al. Detection of occupational exposure to genotoxic agents with urinary mutagen assay. Mutat Res 1983;108:67-79.

46 Kuljukka-Raab T, Nylund L, Vaaranrinta R, et al. The effect of relevan genotypes on PAH exposure-related biomarkers. Journal of Exposure Analysis and Epidemiology 2002;12:81-91

47 Černa M, Hájek V, Dobiáš, et al. Mutagenni aktivita moče pracovniku provozu zpracováni černouhelnèho dehtu. Pracovni Lèkařstvi 1984;2:41-4.

48 De Mèo MP, Dumenil G, Botta AH, et al. Urine mutagenicity of steel workers exposed to coke oven emissions. Carcinogenesis 1987;3:363-7.

49 Clonfero E, Granella M, Marchioro M, et al. Urinary excretion of mutagens in coke oven workers. Carcinogenesis 1995;16:547-54.

50 Hagmar L, Stromberg U, Tinnerberg $\mathrm{H}$, et al. The usefulness of cytogenetic biomarkers as intermediate endpoints in carcinogenesis. Int J Hyg Environ Health $2001 ; 204: 43-7$

51 Møller $\mathbf{P}$, Knudsen LE, Loft $\mathrm{S}$, et al. The comet assay as a rapid test in biomonitoring occupational exposure to DNA-damaging agents and effect of confounding factors. Cancer Epidemiol Biomarkers Prev 2000;9:1005-15. 